\title{
EVALUASI PENGGUNAAN OBAT ANTIHIPERTENSI \\ PADA PASIEN HIPERTENSI RAWAT JALAN DI PUSKESMAS SEMPAJA SAMARINDA
}

\author{
Adam M. Ramadhan, Arsyik Ibrahim, Ayi Indah Utami \\ Laboratorium Penelitian dan Pengembangan FARMAKA TROPIS Fakultas Farmasi \\ Universitas Mulawarman, Samarinda, Kalimantan Timur \\ email: adam@farmasi.unmul.ac.id
}

\begin{abstract}
ABSTRAK
Telah dilakukan penelitian yang bertujuan untuk mengevaluasi penggunaan obat antihipertensi pada pasien hipertensi yang meliputi ketepatan obat, ketepatan dosis, dan kepatuhan pasien dalam meminum obat di Puskesmas Sempaja Samarinda periode bulan Juni 2014. Penelitian ini bersifat analitik observasional dengan metode pengumpulan data prospektif yaitu melakukan wawancara menggunakan kuisioner MMAS kepada 32 pasien hipertensi rawat jalan di Puskesmas Sempaja Samarinda.Pola pengobatan hipertensi yang paling sering digunakan di puskesmas Sempaja Samarinda yaitu Captopril dari golongan ACEI, penggunaan obat menunjukkan ketepatan pemilihan obat dan dosis telah sesuai dengan JNC VII dimana Captopril dari golongan ACEI dan Amlodipine dari golongan CCB diberikan tunggal pada pasien hipertensi stage 1, dan dapat dikombinasi untuk pasien hipertensi stage 2.Dengan dosis dan frekuensi pemberian Captopril $25 \mathrm{mg}, 2 \times 1$; Amlodipine $10 \mathrm{mg}, 1 \times 1$; Bisoprolol $5 \mathrm{mg}, 1 \times 1$; HCT $25 \mathrm{mg} 1 \times 1$; dan ISDN $30 \mathrm{mg}$, $3 \times 1$. Berdasarkan tingkat kepatuhan pasien persentase skor kepatuhan terbanyak yaitu kepatuhan rendah sebesar 50\%, kepatuhan sedang sebesar $25 \%$ dan kepatuhan tinggi $25 \%$. Hasil pengujian kepatuhan pasien menggunakan kuesioner MMAS-8menunjukkan bahwa tidak terdapat hubungan antara kepatuhan pasien dalam meminum obat dengan penurunan tekanan darah pasien.
\end{abstract}

Kata Kunci: Antihipertensi, Hipertensi, Kepatuhan, Morisky scale, Tepat dosis, Tepat obat

\section{PENDAHULUAN}

Hipertensi adalah suatu keadaan seseorang mengalami peningkatan tekanan darah di atas normal, yaitu tekanan darah sistolik $\geq 140 \mathrm{mmHg}$ dan atau tekanan darah diastolik $\geq 90 \mathrm{mmHg}$ (Chobanian, dkk, 2003). Hipertensi mempunyai gejala umum yang ditimbulkan seperti pusing, sakit kepala, rasa berat ditengkuk, sukar tidur, mata berkunang-kunang (Aru, dkk, 2009). Gejala yang timbul pada penyakit hipertensi dapat dicegah dengan cara menurunkan berat badan berlebih (obesitas), pembatasan asupan garam, melakukan olah raga teratur, berhenti merokok dan minum obat secara teratur (Depkes, 2008).

Survei tentang prevalensi hipertensi pada tahun 2007 berdasarkan hasil pengukuran, diagnosis tenaga kesehatan riwayat minum obat hipertensi di temukan; prevalensi hipertensi di Indonesia pada penduduk usia diatas 18 tahun adalah sebesar $31,3 \%$ untuk pria sedangkan wanita mencapai sebesar $31,9 \%$ dari seluruh total penduduk usia > 18 tahun.Angka penderita hipertensi 
mencapai $32 \%$ pada tahun 2008 dengan kisaran penderita berusia > 25 tahun. Jumlah penderita pria mencapai $42,7 \%$, sedangkan $39,2 \%$ adalah wanita (Depkes, 2008).

Kalimantan timur menduduki tingkat ketiga tertinggi pada prevalensi hipertensi di indonesia pada umur $>18$ tahun, yaitu 29,6\% (Depkes, 2014). Data dinas kesehatan kota Samarinda tahun 2007 menunjukan prevalensi hipertensi mencapai $9,9 \%$. Pada profil Puskesmas Sempaja tahun 2013 hipertensi termasuk kedalam 10 penyakit terbesar urutan ke 3 sebanyak 1864 orang atau sebanyak $23 \%$.

\section{METODE PENELITIAN}

\section{Instrumen Penelitian}

Kuesioner kepatuhan Morisky scale, kartu rekam medik pasien dan lembar pengumpul data.

\section{Populasi dan Subjek Penelitian}

Populasi dari penelitian ini adalah penduduk yang mengalami hipertensi di wilayah kerja Puskesmas Sempaja Samarinda pada periode bulan Juni 2014. Subjek dari penelitian ini adalah responden yang diberikan obat antihipertensi oleh petugas kesehatan Puskesmas di wilayah kerja Puskesmas Sempaja Samarinda yang berkunjung ke Poli Umum pada periode bulan Juni 2014 yang memenuhi kriteria inklusi.

\section{Prosedur Penelitian}

Penelitian diawali dengan melakukan survei pendahuluan pada Poli Umum di Puskesmas Sempaja Samarinda. Pasien yang memenuhi kriteria inklusi, diwawancarai dengan menggunakan kuesioner MMAS. Data yang telah didapat kemudian dikumpulkan untuk di olah dan di analisa.

\section{HASIL DAN PEMBAHASAN}

\section{Pola Pengobatan Pasien Hipertensi}

Penelitian ini dilakukan di Puskesmas Sempaja Samarinda. Data yang diperoleh dari kuesioner kepatuhan dan rekam medik berjumlah 32 pasien. Selanjutnya dianalisis penggunaan obat berdasarkan tepat obat, tepat dosis, dan kepatuhan pasien dalam meminum obat antihipertensi.

Pola Pengobatan penderita hipertensi di puskesmas Sempaja dapat dilihat pada tabel 1. dan tabel 2.

Tabel 1. Pola pengobatan pasien hipertensi di puskesmas Sempaja dengan Obat Hipertensi Tunggal

\begin{tabular}{ccccc}
\hline Kategori & Golongan Obat & Jenis & Frekuensi & Persentase \\
\hline \multirow{2}{*}{ Prehipertensi } & ACEI & Captopril & 2 & $7,15 \%$ \\
& CCB & Amlodipine & 1 & $3,57 \%$ \\
\hline Hipertensi & ACEI & Captopril & 7 & $25 \%$ \\
Stage 1 & CCB & Amlodipine & 3 & $10,71 \%$ \\
\hline Hipertensi & ACEI & Captopril & 14 & $50 \%$ \\
Stage 2 & CCB & Amlodipine & 1 & $3,57 \%$ \\
\hline & TOTAL & & 28 & $100 \%$ \\
\hline
\end{tabular}


Tabel 2. Pola pengobatan pasien hipertensi di puskesmas Sempaja dengan Obat Hipertensi Kombinasi

\begin{tabular}{clccc}
\hline Kategori & Golongan Obat & Jenis & Frekuensi & Persentase \\
\hline Prehipertensi & $\begin{array}{l}\text { CCB }+ \text { Nitrat }+\beta \\
\text { Blocker }\end{array}$ & $\begin{array}{c}\text { Amlodipine + ISDN + } \\
\text { Bisoprolol }\end{array}$ & 1 & $25 \%$ \\
\hline Hipertensi & ACEI + CCB & Tanapres $^{(R)}+$ Amlodipine & 1 & $25 \%$ \\
Stage 1 & & & 1 & \\
\hline Hipertensi & CCB + $\beta$ Blocker & Amlodipine + Bisoprolol & 1 & $25 \%$ \\
Stage 2 & ACEI + Thiazid & Captopril + HCT & 1 & $25 \%$ \\
\hline \multicolumn{2}{r}{ TOTAL } & & 4 & $100 \%$ \\
\hline
\end{tabular}

Berdasarkan data pola pengobatan di puskesmas Sempaja menunjukkan bahwa obat yang paling sering digunakan adalah Captopril dari golongan ACEI yaitu pada pasien prehipertensi sebanyak 2 pasien atau $7,15 \%$, pasien hipertensi stage 1 sebanyak 7 pasien atau $25 \%$, dan pada pasien hipertensi stage 2 sebanyak 14 pasien atau 50\%. Captopril menurunkan tekanan darah pada banyak pasien secara teratur, namun ketika terjadi efek samping Captopril berupa batuk kering pemberian Captopril biasanya diganti dengan Amlodipine dari golongan CCB.

\section{Ketepatan Obat}

Ketepatan obat pasien hipertensi di puskesmas Sempaja dapat dilihat dari pola pengobatan yang diberikan. Tabel 3. dan 4. merupakan perbandingan antara pola pengobatan pasien hipertensi berdasarkan literatur JNC VII dengan pola pengobatan hipertensi di Puskesmas Sempaja Samarinda.

Tabel 3. Pengobatan rasional pasien hipertensi menurut JNC VII, 2003

\begin{tabular}{|c|c|c|}
\hline Kategori & Golongan Obat & Jenis \\
\hline Prehipertensi & $\begin{array}{l}\text { Tidak diindikasikan } \\
\text { penggunaan obat antihipertensi. }\end{array}$ & $\begin{array}{c}\text { Tidak diindikasikan penggunaan obat } \\
\text { antihipertensi. }\end{array}$ \\
\hline \multirow[t]{5}{*}{$\begin{array}{l}\text { Hipertensi } \\
\text { Stage } 1\end{array}$} & ACEI & $\begin{array}{l}\text { Captopril; Lisinopril; Benazepril; } \\
\text { Ramipril; Trandolapril; Tanapres }\end{array}$ \\
\hline & $\mathrm{ARB}$ & $\begin{array}{l}\text { Losartan; Valsartan; Candesartan; } \\
\text { Irbesartan; Eprosartan }\end{array}$ \\
\hline & $\beta$ Blocker & Bisoprolol; Atenolol; Metprolol \\
\hline & $\mathrm{CCB}$ & $\begin{array}{c}\text { Amlodipine; Nifedipine; Nicardipine; } \\
\text { Verapamil; Diltiazem }\end{array}$ \\
\hline & Thiazide & HCT; Chlortiladone; Indapamide \\
\hline \multirow[t]{4}{*}{$\begin{array}{l}\text { Hipertensi } \\
\text { Stage } 2\end{array}$} & $\mathrm{ACEI}+\mathrm{CCB}$ & $\begin{array}{c}\text { Benazepril hidroklorida }+ \\
\text { Amlodipine }\end{array}$ \\
\hline & Thiazid + ACEI & HCT + Captopril \\
\hline & Thiazid + ARB & HCT + Losartan \\
\hline & Thiazid $+\beta$ Blocker & HCT + Bisoprolol \\
\hline
\end{tabular}


Tabel 4. Ketepatan penggunaan obat pasien hipertensi di Puskesmas Sempaja Samarinda

\begin{tabular}{clcc}
\hline Kategori & Golongan Obat & Jenis & Nomor Responden \\
\hline Prehipertensi & ACEI & Captopril & 20,26 \\
& CCB & Amlodipine & 19 \\
& CCB + Nitrat $+\beta$ & Amlodipine + ISDN + & 22 \\
& Blocker & Bisoprolol & \\
\hline Hipertensi & ACEI & Captopril & $5,6,7,8,14,16,17$ \\
Stage 1 & CCB & Amlodipine & $21,23,28$ \\
& ACEI + CCB & Tanapress ${ }^{\circ}+$ Amlodipine & 13 \\
\hline Hipertensi & ACEI & Captopril & $3,4,9,10,11,12,15$, \\
Stage 2 & & & $18,27,29,30,31,32,33$ \\
& CCB & Amlodipine & 25 \\
& CCB $+\beta$ Blocker & Amlodipine + Bisoprolol & 24 \\
& Thiazid + ACEI & HCT + Captopril & 1 \\
\hline
\end{tabular}

Berdasarkan tabel 3. dan 4. lini pertama pengobatan hipertensi di Puskesmas Sempaja Samarinda sudah sesuai dengan literatur penatalaksanaan hipertensi JNC VII yaitu dari data yang diperoleh obat anti hipertensi yang paling sering digunakan adalah Captopril dari golongan ACEI, dan Amlodipine dari golongan CCB.

Pasien pre-hipertensi memang tidak memerlukan penatalaksanaan farmakologi. Namun, oleh karena resiko perkembangan pre-hipertensi menjadi hipertensi cukup tinggi, maka dianjurkan untuk selalu melaksanakan pemeriksaan tekanan darah secara berkala.

Pasien dengan nomor responden 13 yang mengkonsumsi kombinasi ACEI dan CCB. Tanapress $^{\circledR}$ (Imidapril) merupakan obat golongan ACEIyang berfungsi untuk mencegah Renin Angiotensin Aldosteron System (RAAS) yang timbul akibat efek hemostatis dari menurunnya cardiac output.

Pasien dengan nomor responden 24 yang memiliki riwayat penyakit jantung diberikan antihipertensi kombinasi golongan $\beta$ blocker seperti
Bisoprolol dengan golongan CCB seperti Amlodipine untuk mencegah terjadinya penyakit jantung koroner.

Pasien dengan nomor responden 1 yang menerima kombinasi obat diuretik Thiazide dengan ACEI dimaksudkan untuk pencegahan terjadinya stroke yang cenderung terjadi pada pasien hipertensi tingkat 2, dari data yang diperoleh tekanan darah pasien yaitu 200/110 mmHg.Pada pasien hipertensi dengan resiko stroke ambang batas tekanan darah sistolik dan diastoliknya adalah $200-220 \mathrm{mmHg} / 110$ $120 \mathrm{mmHg}$.

\section{Ketepatan Dosis}

Kriteria tepat dosis diperoleh dengan menghubungkan antara dosis yang dianjurkan dalam literatur dengan dosis yang diberikan pada pasien hipertensi di Puskesmas Sempaja Samarinda. Berikut merupakan tabel perbandingan dosis obat antihipertensi menurut JNC VII dengan dosis obat yang digunakan oleh pasien hipertensi di Puskesmas Sempaja Samarinda. 
Tabel 5. Dosis Obat Antihipertensi menurut JNC VII, 2003

\begin{tabular}{llcc}
\hline Golongan Obat & \multicolumn{1}{c}{ Obat } & $\begin{array}{c}\text { Dosis Lazim } \\
(\mathrm{mg} / \text { hari })\end{array}$ & $\begin{array}{c}\text { Frekuensi } \\
\text { Pemberian }\end{array}$ \\
\hline ACEI & Captopril; & $25-100$ & $2 \times 1$ \\
& Imidapril (Tanapress $\left.{ }^{\circledR}\right)$ & $5-10$ & $1 \times 1$ \\
CCB & Amlodipine & $2,5-10$ & $1 \times 1$ \\
Diuretik Thiazid & HCT & $12,5-50$ & $1 \times 1$ \\
$\beta$ Blocker & Bisoprolol & $2,5-10$ & $1 \times 1$ \\
Nitrat & ISDN & $5-40$ & $3 \times 1$ \\
\hline
\end{tabular}

Tabel 6. Dosis Obat Antihipertensi di Puskesmas Sempaja Samarinda

\begin{tabular}{llcc}
\hline Golongan Obat & \multicolumn{1}{c}{ Obat } & $\begin{array}{c}\text { Dosis Lazim } \\
(\mathrm{mg} / \text { hari) }\end{array}$ & $\begin{array}{c}\text { Frekuensi } \\
\text { Pemberian }\end{array}$ \\
\hline ACEI & 1.Captopril; & 25 & $2 \times 1$ \\
& 2.Imidapril (Tanapress $\left.{ }^{\circledR}\right)$ & 5 & $1 \times 1$ \\
CCB & Amlodipine & $5-10$ & $1 \times 1$ \\
Diuretik Thiazid & HCT & 25 & $1 \times 1$ \\
$\beta$ Blocker & Bisoprolol & 5 & $1 \times 1$ \\
Nitrat & ISDN & 30 & $3 \times 1$ \\
\hline
\end{tabular}

Berdasarkan tabel 5. dan 6 . penggunaan dosis obat antihipertensi di Puskesmas Sempaja Samarinda telah sesuai dengan JNC VII. Rentang dosis harian Captopril adalah $25 \mathrm{mg}$ sampai $100 \mathrm{mg}$, dengan durasi kerja hingga 6-12 jam, dan frekuensi pemberian 2 kali sehari. Menurut literatur pemberian Captopril sebaiknya diawali dengan dosis 12,5 mg, 2 kali sehari dan ditingkatkan 2 sampai 4 minggu sesuai dengan respon pasien. Rentang dosis Amlodipine yaitu 2,5 mg sampai $10 \mathrm{mg}$, dengan durasi kerja 24 jam dan frekuensi pemberian 1 kali sehari. Pada pasien usia lanjut dosis yang dianjurkanpadaawal terapi 2,5 mg, 1 kali sehari. Bila Amlodipine diberikan dalam kombinasi dengan antihipertensi lain, dosis awal yang digunakan adalah 2,5 mg.

Berdasarkan data yang diperoleh menunjukkan beberapa pasien menerima obat antihipertensi golongan Thiazide, $\beta$ blocker, dan Nitrat. Berdasarkan literatur pemberian Hidroklorotiazid(HCT) harus diawali dengan dosis paling rendah yaitu $12,5 \mathrm{mg} 1$ kali sehari pada pagi hari, untuk menghindari efek samping metabolik, dan efek diuresis pada malam hari. Obat antihipertensi Bisoprolol dari golongan $\beta$ blocker diberikan sesuai dengan literatur yaitu rentang dosis per hari nya 2,5-10 $\mathrm{mg}$ dan frekuensi pemberian 1 kali sehari. Isosorbid Dinitrat (ISDN) memiliki dosis lazim per hari 5-40 mg dengan rentang durasi kerja 1-6 jam tergantung respon pasien. Kelemahan penggunaan Nitrat adalah frekuensi pemberiannya yang mencapai 3 hingga 4 kali sehari.

\section{Kepatuhan Pasien}

Tingkat kepatuhan pasien diperoleh dengan menggunakan kuesioner dan wawancara langsung kepada pasien yang memenuhi kriteria inklusi. Distribusi pasien hipertensi di Puskesmas Sempaja Samarinda berdasarkan tingkat kepatuhannya disajikan dalam tabel 7. 
Tabel 7. Tingkat Kepatuhan Pasien Hipertensi di Puskesmas Sempaja.

\begin{tabular}{lcc}
\hline \multirow{2}{*}{ Tingkat Kepatuhan } & \multicolumn{2}{c}{ Jumlah Pasien } \\
\cline { 2 - 3 } & Frekuensi & Persentase \\
\hline Kepatuhan Rendah & 16 & $50 \%$ \\
Kepatuhan Sedang & 8 & $25 \%$ \\
Kepatuhan Tinggi & 8 & $25 \%$ \\
\hline
\end{tabular}

Tabel 8. Faktor-faktor Penyebab Rendahnya Skor Kepatuhan Pasien

\begin{tabular}{clc}
\hline No. & \multicolumn{1}{c}{ Alasan Pasien } & Frekuensi \\
\hline 1 & Pasien sering kali lupa meminum obat antihipertensi & 17 pasien \\
2 & Pasien lupa meminum obat antihipertensi kemarin. & 13 pasien \\
3 & $\begin{array}{l}\text { Pasien lupa membawa obat saat dalam perjalanan atau saat sedang } \\
\text { diluar rumah. }\end{array}$ & 13 pasien \\
\hline
\end{tabular}

Tabel 9. Korelasi Kepatuhan Pasien dengan Penurunan Tekanan Darah dengan analisis statistik

\begin{tabular}{|c|c|c|c|c|}
\hline & \multicolumn{4}{|c|}{ Correlations } \\
\hline & & & Tekanan darah & Kepatuhan Pasien \\
\hline \multirow{6}{*}{$\begin{array}{l}\text { Spearman's } \\
\text { rho }\end{array}$} & \multirow{3}{*}{$\begin{array}{c}\text { Tekanan } \\
\text { darah }\end{array}$} & $\begin{array}{l}\text { Correlation } \\
\text { Coefficient }\end{array}$ & 1.000 & -0.076 \\
\hline & & Sig. (2-tailed) & . & 0.681 \\
\hline & & $\mathrm{N}$ & 32 & 32 \\
\hline & \multirow{3}{*}{$\begin{array}{c}\text { Kepatuhan } \\
\text { Pasien }\end{array}$} & $\begin{array}{c}\text { Correlation } \\
\text { Coefficient }\end{array}$ & -0.076 & 1.000 \\
\hline & & Sig. (2-tailed) & 0.681 & . \\
\hline & & $\mathrm{N}$ & 32 & 32 \\
\hline
\end{tabular}

Keterangan : $\mathrm{H}_{0}=$ Tidak terdapat hubungan antara kepatuhan pasien dengan penurunan tekanan darah

$\mathrm{Ha}=$ Terdapat hubungan antara kepatuhan pasien dengan penurunan tekanan darah

Keputusan : Jika Sig > 0,05 maka $\mathrm{H}_{0}$ diterima

Jika Sig < 0,05 maka $\mathrm{H}_{0}$ ditolak

Dari hasil perolehan data diketahui pasien dengan tingkat kepatuhan rendah memperoleh persentase sebanyak 50\%. Adapun faktor-faktor yang menyebabkan pasien mendapatkan skor kepatuhan rendah dapat dilihat pada tabel 8 .

Pengujian ada atau tidaknya hubungan antara kepatuhan pasien dan penurunan tekanan darah dilakukan menggunakan metode SPSS statistics 17, yang hasilnya ditabulasi pada Tabel 9.

Dari hasil pengolahan data dengan metode uji korelasi Spearman diketahui nilai signifikan kepatuhan pasien adalah 0,681 yang berarti lebih besar dari 0,05 maka $\mathrm{H}_{0}$ diterima. Nilai koefisien korelasi -0,076, koefisien 
negatif menunjukkan jika variabel X1 mengalami penurunan maka X2 akan mengalami kenaikan, begitu pula sebaliknya. Nilai korelasi akan menentukan arah dari korelasi, nilai 0,00 sampai 0,20 berarti korelasi memiliki keeratan sangat lemah. Sehingga diketahui tidak terdapat hubungan antara kepatuhan pasien dalam meminum obat dengan penurunan tekanan darah pasien.
Penentuan normal atau tidaknya penurunan tekanan darah pasien disesuaikan dengan literatur dimana target nilai tekanan darah yang di rekomendasikan dalam JNC VII adalah pasien tanpa komplikasi <140/90 mmHg, pasien dengan diabetes mellitus $<130 / 80$ $\mathrm{mmHg}$, pasien dengan penyakit ginjal kronis $<130 / 80 \mathrm{mmHg}$.

Tabel 10.Korelasi Kepatuhan Pasien dengan Penurunan Tekanan Darah

\begin{tabular}{|c|c|c|c|c|c|}
\hline \multirow{3}{*}{$\begin{array}{l}\text { Tingkat } \\
\text { Kepatuhan }\end{array}$} & \multicolumn{5}{|c|}{ Jumlah Pasien } \\
\hline & \multicolumn{2}{|c|}{ Penurunan Tekanan Darah } & \multicolumn{2}{|c|}{ Lama Menderita } & \multirow{2}{*}{ Persentase } \\
\hline & Normal & Tidak Normal & Menahun & Tidak Menahun & \\
\hline Rendah & 4 & 12 & 9 & 7 & 500 \\
\hline Total & \multicolumn{4}{|c|}{16 pasien } & $50 \%$ \\
\hline Sedang & 1 & 7 & 5 & 3 & 250 \\
\hline Total & \multicolumn{4}{|c|}{8 pasien } & $25 \%$ \\
\hline Tinggi & 2 & 6 & 4 & 4 & $25 \%$ \\
\hline Total & \multicolumn{4}{|c|}{8 pasien } & \\
\hline
\end{tabular}

Berdasarkan data persen kepatuhan, dan lama menderita hipertensi yang tertera pada tabel 10 . menunjukkan penderita hipertensi terbanyak dengan lama penyakit menahun yaitu 9 pasien dengan penurunan tekanan darah tidak normal sebanyak 12 pasien memiliki tingkat kepatuhan rendah. Akan tetapi dari 8 pasien dengan tingkat kepatuhan tinggi, 6 diantaranya tidak mengalami penurunan tekanan darah dan tetap memiliki riwayat penyakit menahun. Hal ini membuktikan bahwa tinggi rendahnya tingkat kepatuhan pasien tidak berkaitan dengan lama waktu menderita hipertensi dan penurunan tekanan darahnya. Kepatuhan pasien dalam meminum obat antihipertensi saja tidak cukup untuk dijadikan parameter penurunan tekanan darah pasien, faktorfaktor lain yang dapat mempengaruhi tekanan darah seseorang seperti usia, jenis kelamin, merokok, stress, mengkonsumsi garam secara berlebih serta mengkonsumsi alkohol atau obat- obatan yang merangsang peningkatan tekanan darah.

\section{KESIMPULAN}

Pola penggunaan obat antihipertensi pada pasien hipertensi di Puskesmas Sempaja Samarinda berdasarkan golongan obat yang diberikan yaitu ACEI, CCB, $\beta$ blocker, Nitrat, dan diuretik Thiazid. Ketepatan obat dan dosis yang diberikan telah sesuai dengan JNC VII. Hasil pengujian kepatuhan pasien menggunakan kuesioner MMAS-8 diketahui bahwa tidak terdapat hubungan antara kepatuhan pasien dalam meminum obat dengan penurunan tekanan darah pasien.

\section{UCAPAN TERIMA KASIH}

Terima kasih kepada Pimpinan Puskesmas Sempaja Samarinda atas izin dan bantuan yang diberikan selama penelitian. Terima kasih kepada Ibu Ketut, dan saudara Misbah selaku pendamping lapangan. 


\section{DAFTAR PUSTAKA}

1. Bachmann., Verna, L. Baughman. 2009. Drug Information Handbook: 17th Edition. Lexi Comp: USA

2. Aru W, Sudoyo., Bambang, Setiyohadi., Idris, Alwi, dan Marcellus, Simadibrata K. 2009. Buku Ajar Penyakit Dalam Jilid II Edisi 5. Interna Publishing: Jakarta

3. Baxter, Karen., Mildred, Davis., Samuel, Driver., Chloe SAJ, Hatwal., Alison, Marshall. 2008. Stockley's Drug Interactions: 8th Edition. Pharmaceutical Press: UK

4. Chobanian, Aram V., Bakris, George L., Henry R, Black., William C, Cushman, dan Lee A, Green. 2003. Joint National Committee on Prevention Detection, Evaluation, dan Treatment of High Pressure VII. Department of Health and Human Services: USA
5. Depkes RI. 2008.Laporan hasil Riset kesehatan dasar (Riskesdas) Nasional tahun 2007.CV Metronusa prima: Jakarta

6. Depkes RI. 2014.Laporan hasil Riset kesehatan dasar (Riskesdas) Nasional tahun 2013.CV Metronusa prima: Jakarta

7. Sweetman, Sean C., Paul S, Blake., Alison, Brayfield., Julie M, McGlashan, dan Gail C, Neathercoat. 2009. Martindale: The Complete Drug Reference. Pharmaceutical Press: Great Britain. 